Rev. Latinoam. Psicopat. Fund., São Paulo, v. 12, n. 3, p. 604-609, setembro 2009

Pirkola, S., Sund, R., Sailas, E., Wahlbeck, K. “Community Mental-Health Services and Suicide Rate in Finland: a nationwide small-area analysis" The Lancet, v. 373, p. 147-153, Jan. 10, 2009. Hawton, K., Heeringen, K. “Suicide” (seminar), The Lancet, v. 373, p. 1372-1381, Apr. 18, 2009.

Yip, P. "Effects of an Earthshake on Suicide Rates in Nantou, Taiwan” (correspondence)

The British Journal of Psychiatry, v. 194, p. 190, Feb. 2009.

Ohgami, H., Terao, T., Shiotsuki, I., Ishii, N., Iwata, N. "Lithium Levels in Drinking Water and Risk of Suicide" (short report) The British Journal of Psychiatry, v. 194, p. 464-465, May 2009.

Young, A. "Invited Commentary on... Lithium Levels in Drinking Water and Risk of Suicide".

The British Journal of Psychiatry, v. 194, p. 466, May 2009.

Salib, E., Cortina-Borja, M. "Effect of 7 July 2005 Terrorist Attacks in London on Suicide in England and Wales" he British Journal of Psychiatry, v. 194, p. 80-85, Jun. 2009.

\title{
A impossibilidade física da morte na mente de alguém vivo
}

G uilherme G utman

The Physical Impossibility of Death in the Mind of Someone Living é o título dado àquela que é, talvez, a obra máxima do artista plástico inglês, Damien Hirst (1965-). Trata-se de um tubarão-tigre, 
conservado por imersão em formaldeído, dentro de um enorme cubo de vidro que dá à peça toda a portentosa dimensão de 4,3 metros. O tubarão foi “congelado" no centro do cubo (que funciona como uma espécie de vitrine tridimensional) em uma posição que, embora não faça ninguém duvidar do fato óbvio de que ele está morto, provoca certa estranheza, já que causa a impressão de ter sido, digamos assim, apanhado em movimento. Um pouco talvez como as pessoas petrificadas pela lava vulcânica em Pompéia, mas inquietante de um outro modo porque o tubarão de Hirst mantém conservada, e de modo perene, a sua melhor forma física. É quase como se ainda fosse possível sentir medo pela ameaça inerente à sua presença.

A obra do britânico Hirst é fascinante e estranha; um majestoso tubarão em um aquário fake, recolhido no exato instante em que salta da vida para a morte e que, fantasticamente, tal qual a obra plástica nos permite experimentar, reflui da morte para a vida.

Mas como se sabe, a morte é um assunto dos vivos. E, é fato, o assunto tem sido incansavelmente investigado, revirado, eviscerado, meditado e intuído; em especial pelas disciplinas psi e por aquelas que atendem às suas afinidades eletivas: as ciências humanas. Quando o tópico específico é o da inclinação para a morte - tema central no estudo do suicídio, das tentativas de suicídio e dos parassuicídios - os vivos têm todo o material à sua disposição: os dados epidemiológicos, as cartas de despedida, as entrevistas clínicas, a experiência prévia, todo o material acumulado sobre o tema - as hipóteses clássicas, os textos apócrifos, os estudos de raiz biológica, psicanalítica, sociológica, antropológica ou filosófica - as questões jurídicas, os experimentos farmacológicos etc.

Quando percorremos parte desse material, fica a impressão de que a maior parte do que se publica a respeito do tema - pelo menos no caso dos periódicos médicos - focaliza os elementos implicados na avaliação do grau de risco de uma tentativa. Fica também a curiosa sensação de que, embora o tema permaneça assíduo nas publicações psiquiátricas standard, as hipóteses levantadas, específicas a cada artigo lido, seguem os altos e baixos que a popularidade de categorias ou elementos psicopatológicos apresenta na época em que os textos foram escritos. Por exemplo, no The British Journal of Psychiatry, dos dois artigos ${ }^{1}$ sobre suicídio publicados este ano (até junho), um deles é sobre um tema sempre palpitante desde o ataque terrorista de 11 de setembro de 2001 aos EUA: a repercussão

1. Isto é, foram por nós excetuados os textos classificados como short reports, bem como as cartas publicadas no referido período.

O outro artigo é sobre o suicídio nas demências.

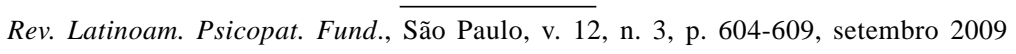


sobre as taxas de suicídio em solo britânico após eventos de julho de 2005 em Londres, que envolveram ataque terrorista suicida por extremistas islâmicos (Salib; Cortina-Borja, 2009). Nessa mesma direção, há uma carta na qual se estima que, o terremoto que flagelou Sichuan, na China, em maio de 2008, repercutirá com um aumento das taxas de suicídio naquela localidade, tal qual aconteceu em Nantou, na República da China, em 1999 (Yip, 2009).

Interessados em obter um vislumbre da presença contemporânea de artigos sobre suicídio na literatura médica, optamos por ler os artigos já publicados em 2009 em duas publicações especializadas: uma representativa da psiquiatria hegemônica européia - o já mencionado The British Journal of Psychiatry - e, a outra, um dos mais respeitados periódicos de medicina interna - The Lancet ponto fundamental de referência teórica e prática para a comunidade médica mundial.

\section{Quando o clínico geral estuda psiquiatria}

Em abril de 2009, foi publicado no The Lancet um seminário sobre suicídio (Hawton; Heeringen, 2009). O teor do texto é o de uma ótima aula, ou um bom capítulo de livro para residentes em psiquiatria, posto que a maioria dos profissionais envolvidos com a promoção de saúde mental conhece - ou deveria conhecer - o conteúdo apresentado na publicação em questão. Assim, se o texto pode ser recomendado para estudantes, para médicos de outras especialidades, ou como uma revisão para "trabalhadores psi” em geral, a sua leitura oferece ainda outro interesse para aqueles interessados em questões epistemológicas: se tomarmos esse seminário como um exemplo privilegiado da matriz psiquiátrica dos conhecimentos e acordos básicos em torno do tema suicídio, então teremos não apenas uma visão daquilo que um clínico terá à sua disposição sobre o assunto, como descobriremos de que solo comum partem as estratégias de prevenção do suicídio que atualmente compõem o arsenal de intervenção de psiquiatras e gestores em saúde. É que, forçados a selecionar e sintetizar aquilo que consideraram imprescindível ensinar sobre o tema, os autores do artigo - ambos de centros de pesquisa em suicídio; um no Reino Unido, outro na Bélgica - acabaram por revelar, entre outras coisas, o modelo etiológico hegemônico para a compreensão das possíveis motivações para o autoextermínio.

Em seu texto, Hawton e Heeringen passeiam por todos os principais tópicos habitualmente estudados: epidemiologia, métodos mais utilizados, fatores contribuintes e, finalmente, as diretrizes preventivas. Como é possível supor, todos 
estes itens estão necessariamente enlaçados; isto é, todas as estratégias de prevenção - tanto em relação aos "grupos de risco" quanto à população como um todo - são elaboradas tendo como alvo o conjunto bastante heterogêneo de coisas que, de um modo ou de outro, aumentam as chances da ocorrência de comportamento suicida.

A hipótese etiológica base, como acontece atualmente em relação a quase qualquer tema psiquiátrico, segue o “modelo estresse-diátese”, encaminhando assim a discussão para a determinação dos elementos que corresponderiam a essa disposição geral e indeterminada que é a diátese, e para aqueles elementos que corresponderiam aos "fatores estressantes". No artigo do The Lancet, os autores apontam num primeiro plano o "pessimismo”, a “desesperança” e a propensão à "agressão” ou à “impulsividade” como os principais componentes da diátese; todavia, não deixam de mencionar outros fatores que também comporiam a diátese, tais como os “familiares e genéticos”, as “experiências da infância” e até mesmo os "níveis de colesterol”. Do lado dos fatores estressantes, citam como fundamentais as “crises psicossociais agudas” e os transtornos psiquiátricos.

Do lado da prevenção, os autores propõem como "estratégias populacionais" as seguintes diretrizes: a restrição aos meios mais frequentemente utilizados; o acesso a tratamento especializado; o monitoramento de como são elaboradas as notícias de tentativas ou de suicídios concretizados; e a internet como um veículo que, na mesma medida que pode promover o suicídio, pode funcionar como um eficiente instrumento preventivo.

Cada um dos itens acima inspira uma discussão relativamente longa, que ultrapassaria em muito as pretensões e a extensão desta resenha. Então, vamos deixar que alguns dos temas presentes nos artigos lidos condicionem a nossa escolha de dois temas que discutiremos brevemente.

\section{Quando o psiquiatra pensa a sua disciplina}

A ideia de profilaxia - tão natural em outras especialidades médicas - sempre foi problemática para a psiquiatria, e a psiquiatria preventiva norte-americana foi provavelmente um dos capítulos mais tristes da história dessa disciplina. Contudo, quando o tema é suicídio, a ideia de prevenção se apresenta sem constrangimentos. Tudo indica que um dos problemas centrais a essa discussão é a necessidade de combinar o que poderíamos chamar de "a cabeça de gestor” e "a cabeça de um clínico”. Como não massificar as condutas e reunir em um mesmo rebanho, razões e necessidades diferentes quando o assunto é a propensão ao suicídio? Ao mesmo 
tempo, quando a responsabilidade é pensar a saúde da população, como não estudar estratégias globais que diminuam o número de mortes?²

Vejamos um item preventivo que aparece mais de uma vez nos artigos lidos.

No seminário publicado no The Lancet, os autores mencionam a utilidade das preparações psiquiátricas do lítio na prevenção do suicídio. A sugestão fundamental é a de que o uso de lítio reduziria consideravelmente (60\% de redução, nos estudos citados por eles) as taxas de morte e de suicídio em pessoas com transtornos de humor. Mas além dos possíveis efeitos propriamente farmacológicos de estabilização do humor e de redução da impulsividade e da agressividade, ressalta-se a possibilidade de que ocorra também um efeito não específico gerado pelo acompanhamento especializado e de longo prazo inerente à utilização de uma medicação como o lítio (Hawton; Heeringen, 2009).

Reencontramos a tematização das relações entre o lítio e as taxas de suicídio em um short report do The British Journal of Psychiatry e em um comentário publicado sobre este texto no mesmo número do periódico. No primeiro (Ohgami et al., 2009), os autores propõem que a presença de lítio na água potável de uma localidade no Japão, implicaria na redução dos níveis populacionais de suicídio. Como os resultados encontrados valem mesmo para níveis muito baixos de lítio (níveis muito distantes do que se considera uma dose terapêutica em um contexto psiquiátrico habitual), não haveria a suposição adicional daquele ganho inespecífico referido no estudo do The Lancet. Muitas questões se apresentam à discussão da hipótese em questão, uma delas levantada pelo comentador, que lembra que, quando se descobriu que o flúor adicionado à água diminuía os índices de cáries na população, surgiu uma série de questionamentos; dos bioquímicos aos estéticos, passando pelo debate sobre os direitos do indivíduo de exercer a sua liberdade de escolha (Young, 2009), da adoção dessa medida de saúde pública. Não é difícil imaginar, quando o objeto de prevenção é o suicídio, quantas outras polêmicas se colocariam em pauta.

A discussão ética em torno da ideia de prevenção em psiquiatria - e da prevenção do suicídio em particular - é, evidentemente, um assunto tão extenso

2. Neste sentido, é interessante que o outro artigo sobre suicídio publicado este ano no The Lancet se debruce exatamente sobre as relações entre taxas de suicídio e os diferentes modos de organização dos serviços de saúde mental na Finlândia (Pirkola, Sund, Sailas, Wahlbeck, 2009). Os resultados encontrados pelos autores demonstram que, na população estudada, há uma diminuição das taxas de suicídios nos serviços abertos em relação ao serviços em regime fechado (internações). 
quanto espinhoso. Há nele tópicos delicadíssimos, como o “direito ao suicídio” ou a responsabilização íntima e pública pelo desejo de morte.

Há publicações que se debruçam sobre essa discussão, e há mesmo um defensor da estatura intelectual de um Michel Foucault, que num texto polêmico, propõe que a sociedade, digamos, permita morrer aqueles que refletidamente, assim o desejam (cf. referências abaixo).

O problema, é que - argumentos da paixão ou da razão (como foi dito no início dessa resenha, há um enorme contingente de material para a pesquisa das motivações para o comportamento suicida) - falta alguma coisa para que fosse possível um posicionamento firme e infalível sobre o tema. Nisso que falta, trata-se exatamente desse refluxo fantástico que cintila por alguns instantes da obra de Damien Hirst, e que flutuando, faz lembrar aos vivos a presença daquela parcela de mistério insondável que resta a cada suicídio logrado.

\section{Referências}

Foucault, M. Um plaisir si simple. In: Dits et ecrits. Paris: Gallimard, 1994. t. III, texte 264.

Guillon, C.; Le Bonniec, Y. Suicide, mode d'emploi: histoire, technique, actualité. Paris: Alain Moreau, 1982.

\section{GuILHERMe Gutman}

Psiquiatra e psicanalista; professor adjunto do Departamento de Psicologia da Pontifícia Universidade Católica do Rio de Janeiro - PUC-Rio (Rio de Janeiro, RJ, Brasil) Rua Visconde de Pirajá, 595/905 - Ipanema 22410-003 Rio de Janeiro, RJ, Brasil

Fone: (21) 9106-7009

e-mail: guilhermegutman@gmail.com 